\title{
Cultura Afro-brasileira na Educação Física escolar: expectativa ou realidade na
}

\section{prática docente?}

\author{
Afro-Brazilian culture in Physical Education at school: expectation or reality in teaching practice? \\ Cultura Afro-brasilera en la Educación Física escolar: ¿expectativa o realidad en la práctica
}

docente?

Recebido: 05/10/2021 | Revisado: 11/10/2021 | Aceito: 14/10/2021 | Publicado: 17/10/2021

\author{
Marieli Nepomuceno de Oliveira \\ ORCID: https://orcid.org/0000-0003-0575-8673 \\ Universidade Federal Rural do Rio de Janeiro, Brasil \\ E-mail: marieli-oliveira08@ hotmail.com \\ Elizangela Cely \\ ORCID: https://orcid.org/0000-0001-5905-9208 \\ Universidade Federal Rural do Rio de Janeiro, Brasil \\ E-mail: elizangela.cely@gmail.com \\ Gabriela Simões \\ ORCID: https://orcid.org/0000-0003-1041-340X \\ Universidade Federal Rural do Rio de Janeiro, Brasil \\ E-mail: gabssimoes9@gmail.com \\ Célia Polati \\ ORCID: https://orcid.org/0000-0001-9047-184X \\ Universidade Federal Rural do Rio de Janeiro, Brasil \\ E-mail: celiapolati@gmail.com
}

\begin{abstract}
Resumo
Objetivou-se analisar como professores de educação física compreendem a Lei 10.639/03 e se abordam a cultura afrobrasileira em suas aulas. Para isso, adotou-se uma abordagem qualitativa, de caráter descritivo e de delineamento transversal. Participaram da pesquisa 10 professores de Educação Física provenientes de duas escolas da rede pública de ensino. Os dados foram coletados mediante entrevista semiestruturada e tratados a partir da técnica de análise de conteúdo. Os resultados indicaram que a maioria dos professores desconhece a Lei 10.639/03, com ausência de contato na formação profissional. Dos conteúdos mais desenvolvidos em suas aulas, destacaram-se os jogos, seguidos de esportes e dança, sendo o étnico-racial menos mencionado. Em relação à abordagem dos conteúdos relativos à cultura afro-brasileira, apenas uma professora afirmou trabalhar tais conteúdos perpassando o ano letivo e o currículo da disciplina. Das dificuldades mencionadas, destacou-se o preconceito da comunidade escolar em relação à temática, ainda que os professores considerem importante o trato desses conteúdos, sobretudo em função da diversidade, miscigenação e preconceito racial presentes na sociedade brasileira. Diante disso, concluiu-se que ainda existem lacunas tanto em relação à formação de professores (inicial e continuada) quanto em função do conhecimento, legitimação e aplicabilidade da Lei 10.639/03 e os conteúdos da cultura afro-brasileira no ambiente escolar.
\end{abstract}

Palavras-chave: Escola; Lei 10.639/03; Formação profissional; Licenciatura; Relações étnico-raciais.

\begin{abstract}
Its objective was to analyze how Physical Education teachers understand Law 10.639/03 and approach Afro-Brazilian culture in their classes. For this, a qualitative, descriptive and cross-sectional procedure was adopted. Ten Physical Education teachers from two public schools participated in the research. Data were collected through semi-structured interviews and treated using the content analysis technique. The results indicated that most teachers are unaware of Law 10.639/03 and that they had no contact with it during their professional training. Of the most developed content during their classes, games stood out, followed by sports and dance, being the least mentioned ethnic-racial issue. Regarding the approach to the contents related to the Afro-Brazilian culture, only one teacher affirmed to work on such contents throughout the academic year and in the subject program. Of the difficulties mentioned, the prejudice of the school community in relation to the theme stood out, even though teachers consider it important to deal with these contents, especially due to the diversity, miscegenation and racial prejudice present in Brazilian society. Therefore, it was concluded that there are still gaps both in relation to teacher training (initial and continuing) and in terms of knowledge, legitimacy and applicability of Law 10.639/03 and the contents of Afro-Brazilian culture in the school environment.
\end{abstract}

Keywords: School; Law 10.639/03; Professional qualification; Bachelor's degree; Ethnic-racial relations. 


\begin{abstract}
Resumen
Tuvo como objetivo analizar cómo profesores de Educación Física comprenden la Ley 10.639/03 y abordan la cultura afro-brasilera en sus clases. Para ello, se adoptó un abordaje cualitativo, de carácter descriptivo y de delineamiento transversal. Participaron de la investigación 10 profesores de Educación Física provenientes de dos escuelas de la red pública de enseñanza. Los datos fueron colectados mediante entrevista semi-estructurada y tratados a partir de la técnica de análisis de contenido. Los resultados indicaron que la mayoría de los profesores desconoce la Ley 10.639/03 y que no tuvieron contacto con ésta durante su formación profesional. De los contenidos más desarrollados durante sus clases se destacaron los juegos, seguidos por los deportes y la danza, siendo el asunto étnico-racial menos mencionado. En lo que respecta al abordaje de los contenidos relacionados a la cultura afro-brasileira, sólo una profesora afirmó trabajar dichos contenidos a lo largo del año lectivo y en el programa de la materia. De las dificultades mencionadas, se destacó el prejuicio de la comunidad escolar en relación a la temática, a pesar de que los profesores consideren importante tratar esos contenidos, sobretodo en función de la diversidad, mestizaje y discriminación racial presentes en la sociedad brasileira. Ante ello, se concluye en que aún existen lagunas tanto en relación a la formación de profesores (inicial y continuada) como en función del conocimiento, legitimación y aplicabilidad de la Ley 10.639/03 y los contenidos de la cultura afro-brasilera en el ambiente escolar.
\end{abstract}

Palabras clave: Escuela; Ley 10.639/03; Formación profesional; Licenciatura; Relaciones étnico-raciales.

\title{
1. Introdução
}

A cultura pode ser definida como a herança de valores e de objetos compartilhados por um grupo humano relativamente coeso (Bosi, 1992). Tendo em vista essa herança, sabe-se que a formação da população brasileira ocorreu a partir da miscigenação de diferentes povos, tendo como principal base as origens Africana, Indígena e Portuguesa. Somada a diversidade de etnias, vieram para o Brasil inúmeras culturas que contribuíram para a história e a estruturação do país. Contudo, embora presente a diversidade, no Brasil, o racismo culminou com estratégias para manter os negros às margens de seus direitos e de sua cidadania, principalmente daqueles que reconhecem sua ascendência e que não a assimilam com construções depreciativas em relação as suas raízes étnico-raciais (Silva, 2016).

Por isso, tornaram-se necessárias políticas públicas que reparassem as desigualdades e o desrespeito, visando garantir a todos os brasileiros igualdade de direito, história e cultura. Em prol da valorização da origem dos brasileiros, majoritariamente negros, de acordo com o Instituto Brasileiro de Geografias e Estatística - IBGE (Brasil, 2016a), em 2003 foi sancionada a Lei ${ }^{\circ}$ 10.639/03, alterando a Lei de Diretrizes e Bases da Educação Nacional (Brasil, 1996), incluindo a obrigatoriedade do estudo de História e Cultura Afro-Brasileira no ensino fundamental e ensino médio (Brasil, 2003a). Além disso, no mesmo ano, foi aprovado o Decreto $n^{\circ} 4.886 / 03$ que estabeleceu a Política Nacional de Promoção da Igualdade Racial (PNPIR), possibilitando que o educando resgate sua identidade, com vistas ao respeito e igualdade (Brasil, 2003b).

A educação é um processo social amplo (Kruppa, 2016). Neste sentido, a educação nacional tem como finalidades o pleno desenvolvimento do educando, seu preparo para a cidadania e sua qualificação para o trabalho. Ainda, abrange processos formativos que se desenvolvem, dentre outros, nas manifestações culturais (Brasil, 1996). Dessa forma, a escola é uma instituição responsável pela formação humana e cidadã, na qual os educandos irão construir relações sociais, reconhecer sua identidade e conviver com a diversidade. Posto isso, cabe também a comunidade escolar o compromisso com a superação da discriminação e do preconceito, tornando-se imprescindível conhecer, reconhecer, respeitar, valorizar e vivenciar as diferentes manifestações culturais, como as manifestações da cultura afro-brasileira, a qual está presente em nossa cultura (Bento, 2012).

A presença negra nas manifestações culturais brasileiras inclui: o esporte, a linguagem falada, escrita e gestual, o vestuário, as artes, a filosofia de vida, a religiosidade, a musicalidade que, embora não reconhecida, é vivida e transmitida, acima de tudo pelas camadas populares, resistindo ao esmagamento sociocultural e histórico a que foram submetidas (Filho, 2006). No entanto, normalmente o conteúdo proposto nas escolas continua seguindo a educação tradicional, isto é, a transmissão da imagem do negro reduzida ao escravizado, marginal, pobre e inferior. Ao encontro, Anjos (2005) afirma que a escola tem funcionado como uma espécie de segregadora informal. Isto, pois, a ideologia subjacente a essa prática de distorção das comunidades afrodescendentes e de seus valores busca não oferecer modelos relevantes que ajudem a construir uma 
autoimagem positiva. Nesse sentido, o papel da escola em função da diversidade não tem sido cumprido no ambiente escolar.

Em virtude desse sistema educacional excludente, acontecem frequentemente casos de racismo e discriminação no cotidiano escolar. Nesses contextos, por exemplo, alguns professores acabam por considerar naturais tais práticas, relevando o racismo velado - "[...] aquele que opera nas margens da invisibilidade, sem ferir frontalmente suscetibilidades já postas como naturais, operando de forma subliminar, como ocorre no caso das piadas e brincadeiras." (Pereira, 2011, p. 157). Dessarte, cabe questionar: que contribuição a escola está garantindo na construção da identidade e na representatividade dos alunos negros? Como está sendo ensinada aos alunos a igualdade na valorização cultural e social?

Especificamente a Educação Física (EF) - componente curricular obrigatório da Educação Básica (Brasil, 1996), tem como um dos objetivos auxiliar os alunos em sua percepção do mundo e da cultura, incluindo a valorização da diversidade responsável pela formação do Brasil atual, de forma que cada aluno seja representado e capaz de conhecer suas origens. Face a isso, embora o trato dos conteúdos referentes à história e cultura afro-brasileira seja realizado especialmente nas áreas de literatura e histórias brasileiras e educação artística, estes, ainda, deverão estar presentes em todo o currículo escolar (Brasil, 1996). Por sua vez, é de extrema importância que na EF sejam propostos e trabalhados esses conteúdos, de forma a fortalecer a luta contra a desigualdade racial.

Após dezoito anos desde a aprovação da Lei $n^{\circ} 10.639 / 03$, autores indicam que a cultura afro-brasileira ainda não é abordada nas aulas de EF escolar efetivamente (Maranhão, 2009; Bento, 2012) e que, além disso, ainda há resistência e percalços no desenvolvimento de seus conteúdos na disciplina (Silva, et al., 2019). Em consequência, alunos que não vivenciam tais experiências na escola tendem a seguir para a sociedade com esse conhecimento segregado, podendo contribuir para a discriminação e intolerância racial e religiosa, assim como outros preconceitos. Também por esses motivos, indica-se a necessidade e relevância de aprofundamento acerca dessa temática (História da África, africanos e afro-brasileiros), sobretudo para professores da educação básica (Lima, et al., 2020). Nessa lógica, esse estudo teve por objetivo analisar como professores de EF compreendem a Lei 10.639/03 e se existe abordagem da cultura afro-brasileira em suas aulas. Para este fim, buscou-se identificar o conhecimento dos professores acerca da Lei nº10.639/03; os conteúdos mais abordados em suas aulas, bem como se havia inclusão de conteúdo(s) relacionado(s) à cultura afro-brasileira; se os professores tiveram contato com conteúdos relativos a cultura afro-brasileira na formação (inicial e/ou continuada); possíveis dificuldades para o desenvolvimento dos conteúdos relacionados às manifestações afro-brasileiras nas aulas; e, por fim, as percepções dos professores acerca da importância da inclusão dos conteúdos relativos a cultura afro-brasileira nas aulas.

\section{Fundamentação Teórica}

\subsection{Educação para as relações étnico-raciais}

Reconhecendo a urgência de uma medida em prol da igualdade racial para redução da discriminação, em 2003 foi aprovada a alteração na LDBEN (Brasil, 1996), que autenticou a Lei n 10.639/03 e incluiu o artigo 26-A que determina que todas as escolas de ensino fundamental e ensino médio deverão ensinar a história e cultura afro-brasileira em seus respectivos espaços. Ainda, na referida Lei de 2003, determina-se que:

$\S 1^{a}$ - O Conteúdo programático a que se refere o caput deste artigo incluirá o estudo da História da África e dos Africanos, a luta dos negros no Brasil, a cultura negra brasileira e o negro na formação da sociedade nacional, resgatando a contribuição do povo negro nas áreas social, econômica e política pertinentes à História do Brasil.

$\S 2^{\mathrm{a}}-$ Os Conteúdos referentes à História e Cultura Afro-Brasileira serão ministrados no âmbito de todo o currículo escolar, em especial nas áreas de Educação Artística e de Literatura e História Brasileiras (Brasil, 2003a). 
No ano seguinte, foi publicado o Parecer $\mathrm{N}^{\circ} \mathrm{CNE} / \mathrm{CP}$ 003/2004, buscando regulamentar a alteração da LDBEN ${ }^{\circ}$ 9.394/96, tratando sobre as Diretrizes Curriculares Nacionais para a Educação das Relações Étnico-Raciais e para o Ensino de História e Cultura Afro-Brasileira e Africana. Pode-se considerar que este foi um passo em prol da mudança social por meio de uma reforma educacional, tendo em vista que essas Diretrizes Curriculares preveem que para a Lei $n^{\circ}$ 10.639/03 se efetivar deverão acontecer diversas mudanças, como atualização e suporte para os professores, mudança no currículo dos cursos de ensino superior, edição dos materiais didáticos fornecidos para as escolas, entre outras. É possível observar tais mudanças no trecho apresentado abaixo:

Art. $6^{\circ}$ Os sistemas de ensino e as entidades mantenedoras incentivarão e criarão condições materiais e financeiras, assim como proverão as escolas, seus professores e alunos de material bibliográfico e de outros materiais didáticos necessários para a educação das Relações Étnico-Raciais e o Ensino de História e Cultura Afro-Brasileira e Africana; as coordenações pedagógicas promoverão o aprofundamento de estudos, para que os professores concebam e desenvolvam unidades de estudos, projetos e programas, abrangendo os diferentes componentes curriculares (Brasil, 2004a, p. 20).

Apesar do sancionamento da Lei $\mathrm{n}^{\circ} 10.639 / 03$ ser considerado uma conquista significativa, sua aprovação não foi o suficiente para efetivar mudanças no âmbito educacional. Em concordância com Santos (2005), a Lei n ${ }^{\circ}$ 10.639/03 apresenta falhas que podem impedir sua implementação curricular e o fim da cultura eurocêntrica do sistema de ensino brasileiro. A cultura europeia segue supervalorizada em relação às demais culturas, comprometendo a identidade e valorização de outras etnias. De acordo com Carreira e Souza (2013), o Projeto Político Pedagógico é demasiadamente elaborado sem pensar na diversidade existente no contexto escolar, cooperando para a inferiorização de uma parcela significativa da comunidade presente nesse ambiente.

Santos e Souza (2014) destacam que as políticas promovidas pelo Estado impediram o acesso da população negra a diversos espaços sociais, como as escolas, as quais os escravos e negros africanos, ainda que fossem livres, eram proibidos de frequentar. Mesmo após o início do regime republicano não houveram mudanças relevantes na situação social dos negros, pois a Constituição definiu que a união deveria estimular a educação eugênica. Essa exclusão dos negros da sociedade e da educação se perpetua desde o Brasil império, quando seus direitos e acesso à educação foram comprometidos. Hoje, enquanto o país acredita no mito da democracia racial, ainda existem reflexos da segregação e inferiorização advindas do passado, principalmente na educação e nas escolas. Assim como afirma Henriques (2002), a escolaridade entre os negros é menor do que entre os brancos.

A desvalorização do negro e de sua cultura compromete sua inclusão social em diversos meios, pois o mesmo não se vê representado nas esferas sociais, nas quais quase sempre sua imagem é subalternizada. Seja na mídia, no espaço escolar ou no ambiente profissional, é notória a superestimação europeia. Essa situação entra em contradição com o perfil do país que é majoritariamente formado pela população negra, como mostram os dados da Pesquisa Nacional por Amostra de Domicílios (PNAD), realizada pelo IBGE (Brasil, 2016b).

Os diversos materiais didático-pedagógicos usados nas aulas, que geralmente apresentam apenas pessoas brancas como referência positiva, também são responsáveis pela disseminação do preconceito no cotidiano escolar. Normalmente, os negros aparecem nesses materiais só ilustrando a escravização e/ou em situações de desprestígio social (Cavalleiro, 2005). Segundo Munanga (2015) até negou-se que o continente africano teve uma história antes das invasões coloniais. Nas escolas o que ainda se vê é o silenciamento da contribuição dos negros para a construção do país, cuja luta e identidade são reduzidas à escravização, como se não houvesse existência da vida negra antes e depois da diáspora, desta forma, a abolição está inscrita, mas esvaziada de sentido. 
Além de ser um fator potencialmente responsável pela reprodução da exclusão racial, a falta de representatividade no ambiente escolar também compromete a identidade e o rendimento dos alunos negros. Por isso há de se questionar as formas com que a escola lida com a diversidade cultural ali presente e sua responsabilidade na formação de seus respectivos alunos. Munanga (apud Henriques, 2002) indica que a soma do preconceito enraizado na cabeça do professor, sua incapacidade em lidar com a diversidade, o conteúdo discriminatório dos materiais didáticos e as relações preconceituosas entre alunos de diferentes etnias e culturas, desestimulam o aluno negro e interferem em seu aprendizado. Tal cenário reflete no coeficiente de repetência e evasão escolares elevados dos alunos negros, quando comparado aos alunos brancos. Como exemplos,

[...] Histórias sobre quem descobriu o Brasil ainda aparecem nos materiais didáticos e nos currículos praticados nas salas de aula com os estudantes. São frequentes as denúncias de intolerância religiosa com crianças candomblecistas nos espaços escolares. Práticas de subalternização explícita dos referenciais, das culturas e traços identitários das populações pretas e pardas (dos negros) são denunciadas e mapeadas em teses e dissertações acadêmicas. Os entraves são desafiadores. Esses obstáculos se retroalimentam e se perpetuam. São nuances das urgências de uma realidade multicultural invisibilizada pelo ideário da democracia racial (Miranda \& Rosa, 2014, p. 162).

Devido às diversas relações sociais formadas na escola, esse ambiente pode ser considerado um meio capaz de construir positivamente ou negativamente a identidade dos alunos que ali frequentam. Normalmente, o que se vê é a disseminação de estereótipos, a exclusão e a negação à diversidade cultural. A identidade negra é uma construção social que implica a construção do olhar de um grupo étnico-racial sobre si mesmo a partir da relação com o outro, por isso é difícil construir uma identidade negra positiva convivendo num imaginário pedagógico que vê e trata os negros de maneira desigual (Gomes, 2002).

As medidas existentes que buscam a redução do racismo institucional, como a implementação da Lei $\mathrm{n}^{\circ}$ 10.639/03, ainda não anulam a discriminação no cotidiano escolar. Os alunos negros passam por situações constrangedoras como, por exemplo, piadas sobre seu cabelo, seu aspecto físico e seu intelecto, prejudicando-os de inúmeras formas, como indicado por Cavalleiro (2005, p. 12),

Em estudos anteriores, foi possível comprovar que a existência do racismo, do preconceito e da discriminação raciais na sociedade brasileira e, em especial, no cotidiano escolar acarretam aos indivíduos negros: auto-rejeição, desenvolvimento de baixa auto-estima com ausência de reconhecimento de capacidade pessoal; rejeição ao seu outro igual racialmente; timidez, pouca ou nenhuma participação em sala de aula; ausência de reconhecimento positivo de seu pertencimento racial; dificuldades no processo de aprendizagem; recusa em ir à escola e, conseqüentemente, evasão escolar. Para o aluno branco, ao contrário acarretam: a cristalização de um sentimento irreal de superioridade, proporcionando a criação de um círculo vicioso que reforça a discriminação racial no cotidiano escolar, bem como em outros espaços da esfera pública.

Frente à tais consequências para esses alunos, é necessário que a reprodução da discriminação racial na esfera educacional seja constantemente observada sob olhares atentos dos profissionais que ali atuam, para que essa prática seja interrompida. Todos os professores têm o dever de combater e negar o racismo, bem como de promover a possibilidade de falar sobre a diversidade humana. No cotidiano escolar, considerável parte dos profissionais da educação declaram não perceber as discriminações raciais entre os próprios alunos e entre professores e alunos. Essa falta de sensibilidade à percepção de situações conflitantes faz com que a exclusão e o racismo se enraízem na realidade escolar (Cavalleiro, 2005).

Para que o ambiente escolar seja propício à educação das relações étnico-raciais é necessário que a transformação comece pela esfera curricular, sem que a cultura e história afro-brasileira seja abordada com seu significado esvaziado. Isso, pois, a Lei $\mathrm{n}^{\circ} 10.639 / 03$ só poderá ser considerada um passo no processo de ruptura epistemológica e cultural na educação brasileira se as questões raciais no currículo e as mudanças oriundas da obrigatoriedade do ensino de História da África e das 
culturas afro-brasileiras não forem confundidas com novos conteúdos ou como mais uma disciplina. Trata-se de uma mudança estrutural, conceitual, epistemológica e política (Gomes, 2002).

Educar para as relações étnico-raciais vai além de discutir acerca do conteúdo, mas ultrapassar as raízes colonizadoras que ainda se fazem presentes no sistema educacional e social da atual conjuntura. Esse processo deve ser visto como um ato revolucionário com a participação de toda a comunidade escolar, que inclui a família, os professores, os gestores e os demais envolvidos. Por isso, Carreira e Souza (2013) afirmam que assumir o compromisso de sustentar uma educação antirracista requer que a escola aprenda a se comunicar com a diversidade presente naquele espaço, assumindo cada pessoa como sujeito histórico, que têm necessidades e desejos. Assim, a atuação em sala de aula exige um trabalho mais complexo ao se considerar as diferentes maneiras de ser, o que torna necessário desenvolver ações que possibilitem a valorização de todos.

\subsection{Cultura afro-brasileira nas aulas de educação física}

A EF brasileira passou por diversos momentos históricos e políticos relacionados a organizações militares e médicas que explicam os resquícios que ainda se fazem presentes nos conteúdos abordados nas escolas. Mesmo passando por essas fases e suas respectivas tendências pedagógicas, até recentemente a questão racial não era uma pauta discutida com frequência na área, como afirma Bento (2012),

No ambiente escolar pouco ou quase nada tem se discutido sobre as relações étnico-raciais, quer seja nas aulas de educação física, quer seja nos demais componentes curriculares (História, Língua Portuguesa, Matemática, Geografia, Artes, Biologia, entre outros). A história e cultura dos povos indígenas e africanos, não raro, se restringem a alguns conteúdos ilustrativos realizados em datas comemorativas (19 de abril - Dia o Índio; 13 de maio - Dia da Libertação dos Escravos; 20 de novembro - Dia da Consciência Negra) não perpassando o dia a dia na escola, muito menos de forma crítica (p. 28).

A dificuldade em incluir a cultura afro-brasileira nos currículos é uma consequência dos interesses políticos brasileiros que se refletiram na EF desde o século XIX, quando os higienistas buscavam melhorar a qualidade de vida dos trabalhadores industriais e da população que se encontrava num estado de saúde e pobreza deploráveis. A ideia era colocar em pauta o corpo e a conscientização de cuidados sobre o mesmo, pois o corpo do homem era uma riqueza para as indústrias e economia do país devido à sua mão de obra. No início deste século, as influências militares já eram grandes e havia um questionamento sobre o motivo do país não se desenvolver. Com isso, surgiram convicções de alguns teóricos eugenistas de que o Brasil era um país longe de se ascender economicamente devido à sua mestiçagem, responsável por enfraquecer a população, tendo em vista que o gene dos negros era considerado atrasado intelectualmente (Góis Junior, 2000).

Somado a isso, o Brasil tinha que ser bem visto pelos estrangeiros e, com o intuito de melhorar sua imagem as elites brasileiras, buscaram “embranquecer” o país. Já na metade deste século apareceram intelectuais como Fernando de Azevedo, que defendiam que as condições sociais, econômicas e educacionais eram mais significativas que os determinantes raciológicos. Fernando de Azevedo, um dos principais colaboradores do Movimento dos Pioneiros da Escola Nova, interligava o problema higienista com o educacional e tentou unir os dois como meio para solucionar o problema vigente social. No seu programa a EF junto com a educação higiênica passou a se destacar (Góis Junior, 2000).

Ainda na metade do século XIX, a preocupação da EF com a saúde do corpo se estendeu para a necessidade da educação moral e o esporte passou a ser visto como um meio educacional. Segundo Darido (2001), no início da década de 70 o governo militar apoiou a EF na escola buscando a formação de uma juventude forte e saudável, sendo o conteúdo esportivo enraizado na escola, reforçando valores como a racionalidade, a eficiência e a produtividade. A esportivização abraçava a ideia de superioridade do corpo branco, refletida na imagem helênica corporal mitologicamente ambicionada, assim a imagem e identidade do negro era cada vez mais apagada, tendo em vista que o ideal de corpo perfeito para EF era inspirado nos gregos, 
que são brancos (Moreira \& Silva, 2018). Assim, percebe-se que "[...] as representações de corpo negro e corpo indígena na escola e na educação física seguem ideologias dominantes que historicamente segregam saberes destas culturas. [...]”. Tal segregação é decorrente "[...] da percepção de que a Educação Física encontra em seu percurso histórico dificuldades para associar o seu objeto de investigação à questão étnico-racial.” (Moreira \& Silva, 2018, p. 198).

A persistente exclusão dos conteúdos relacionados às questões étnico-raciais nas aulas de EF é resultado também da herança deixada pela esportivização no século XIX, tendo em vista a ainda predominância da prática de esportes específicos, com caráter quase que unicamente procedimental, o que acaba por ignorar a importância dos conceitos, atitudes e valores, bem como de outros conteúdos. Dessa forma, a EF escolar é frequentemente desenvolvida a partir de conteúdos associados aos esportes, o que reduz o acesso dos alunos ao contato com outras práticas corporais, como: jogos, brincadeiras, danças, lutas, contação de histórias e outras manifestações provenientes de diferentes povos e culturas (Bento, 2009).

Tal limitação acerca dos conteúdos abordados nas aulas de EF se contrapõe aos objetivos previstos e recomendados pelos Parâmetros Curriculares Nacionais que, para além dos três blocos de conteúdos, apresenta como um dos temas transversais a pluralidade cultural (Brasil, 1997). O objetivo desse tema transversal é desenvolver o respeito e a valorização às culturas presentes no Brasil, de forma a contribuir para uma convivência mais harmoniosa em sociedade, repudiando todas as formas de discriminação (Darido, et al., 2001). Além disso, essa limitação em relação aos conteúdos contrapõe-se também frente a gama de práticas corporais previstas para a disciplina, de acordo a Base Nacional Curricular (Brasil, 2017).

Por utilizar o corpo em suas aulas, a EF é considerada promotora de cultura e, por isso, é preciso entendê-la como uma disciplina com grande potencial para trabalhar a cultura afro-brasileira. Cada corpo presente na escola carrega história, cultura e subjetividades, sendo imprescindível que todos se sintam representados e tenham suas identidades construídas. No entanto, geralmente as aulas de EF permanecem silenciando o corpo negro, o qual frequentemente é submetido a humilhações que são veladas, como brincadeiras naturais do cotidiano. Tal realidade é relatada na pesquisa de Oliveira e Daolio (2010):

Em relação ao preconceito relacionado aos negros, observamos uma situação em que este fato foi encenado. Numa certa aula, a professora propôs um jogo misto de voleibol, para desânimo de alguns. Mateus, um menino negro que tinha ficado de fora deste jogo para conversar com uma menina na arquibancada, sofria ofensas de seus colegas que jogavam. A ofensa que mais se repetiu foi chamar Mateus de "Maguila" e outras derivações, buscando fazê-lo desistir da aparente paquera e jogar, o que ocorreu em seguida. Em quadra, no decurso do jogo, Mateus errou um lance de finalização de uma jogada, fato suficiente para que um de seus colegas afirmasse veementemente e em alta voz: "É por isso que você é preto!

Neste caso, o fato de ser negro imputou-o o rótulo de menos capaz, bem como, no entendimento de quem o ofendeu, de fator primordial para o "erro" da jogada. Como se o fato de ser negro tivesse alguma relação com o gesto técnico realizado. No entanto, o mesmo era ovacionado no futebol. Mas, por quê? Talvez pelo fato de ser habilidoso com a bola nos pés? É possível. Porém, percebemos que sua popularidade era tamanha no futebol nem tanto por sua habilidade, mas pelo jeito "malandro" como jogava, jeito esse também estereotipadamente relegado aos negros, que, especificamente no Brasil, ainda levam o rótulo de apreciadores de samba e carnaval. (p. 159).

Para Soares (2017) este grupo racial merece um espaço maior para discussão e reflexão no contexto escolar, pois será a partir de vivências e discussões que estes alunos poderão entender suas origens e, desta maneira, construir uma identidade étnica positiva. Por isso, é preciso considerar a atuação da EF escolar como prática cultural. Qualquer abordagem de EF que negue a dinâmica cultural referente à condição humana poderá acabar por se distanciar de um dos seus objetivos: o ser humano como fruto e agente de cultura (Daólio, 2005).

$\mathrm{Na} \mathrm{EF}$, atualmente, a ideia de ensinar apenas o gesto motor correto está ultrapassada. O professor de EF deve problematizar e desenvolver com seus alunos as diversas manifestações da cultura corporal para que estes entendam os sentidos que circundam as práticas corporais. Na disciplina, precisam ser propostos aos alunos conteúdos e estratégias adequadas. Não é possível permitir a continuidade da exclusão que tem caracterizado a EF na escola. Todos os alunos devem 
ter acesso ao conhecimento produzido pela cultura corporal (Darido, 2001). Por ser uma disciplina na qual os alunos têm maior liberdade para se expressar corporalmente, a EF possui diversas possibilidades para trabalhar a cultura afro-brasileira em suas aulas, seja por meio de esportes, jogos, danças, brincadeiras, lutas, entre outros.

Introduzir a cultura afro-brasileira nas aulas da disciplina é um caminho eficaz para desconstruir os estereótipos criados sobre os negros e sua cultura. No entanto, mesmo diante de tantas possibilidades para inserção da cultura afrobrasileira nas aulas, ainda existem poucas produções que valorizam e colaboram para a educação antirracista. Até a prática corporal de raiz africana mais conhecida, como a capoeira, dificilmente é explorada na disciplina e quando ocorre geralmente se reduz a repetição de movimentos descontextualizados e sem sentido. Além disso, existem barreiras culturais que atravessam a inserção da capoeira na escola, como o preconceito religioso, isto é, a associação da capoeira às religiões de matriz africana, de forma a reduzi-las e desmerece-las, legitimando religiões europeias como aquelas verdadeiramente divinas (Silva, et al., 2019).

Ademais, um dos motivos da ausência de abordagem da cultura afro-brasileira nas aulas de EF é fruto de os professores ainda encontrarem dificuldades, sendo estas provenientes da formação (falta de apropriação da temática), como mencionado no estudo de Silva e Filho (2013), assim como pela falta de amparo do Estado e/ou à negação acerca da importância e efetividade em respeitar a pluralidade cultural e a Lei ${ }^{\circ} 10.639 / 03$. Sendo assim, apesar de existirem Documentos Legais em prol da diversidade, com o intuito de reduzir a discriminação racial, ainda há resistência em implementar esse conteúdo no currículo e nas aulas de EF, o que contribui para a construção de uma percepção negativa em relação a África e a cultura afro-brasileira.

Nessa perspectiva, de acordo com Moreira e Silva (2010), é preciso superar a visão pedagógica conteudista predominantemente branca, buscando visibilizar as manifestações que afirmem a cultura afro-brasileira e indígena. Não se trata apenas de defender a inclusão de mais conteúdos nas aulas de EF ligados à cultura afro-brasileira ou indígena, mas que estes conteúdos sejam abordados de forma a contextualizar e legitimar sua validade civilizatória.

\section{Metodologia}

\subsection{Modelo de pesquisa}

Adotou-se uma abordagem qualitativa de pesquisa (Minayo, 2002), de caráter descritivo (Gil, 2008) e de delineamento transversal (Thomas, et al., 2012). Esse estudo apresenta os resultados de um Trabalho de Conclusão de Curso produzido na Licenciatura em Educação Física da Universidade Federal Rural do Rio de Janeiro.

\subsection{Amostra}

A amostra foi composta por dez professores da rede pública de ensino, de ambos os sexos, provenientes de uma escola do município do Rio de Janeiro e uma escola do município de Seropédica, sendo estes selecionados a partir de dois critérios, a saber: formados em licenciatura em $\mathrm{EF}$ e que estivessem atuando no ensino fundamental e/ou médio durante o ano vigente da entrevista (2018). Destes, nove informaram possuir formação em licenciatura em EF e uma, para além dessa formação, possui formação em dança (Professora F). Ademais, sete professores estavam atuando no ensino fundamental (Professores A, D, F, G, H, I e J), dois no ensino médio (Professores C e E) e um em ambos os níveis de ensino (Professor B).

Com o intuito de manter o anonimato previamente garantido, os professores foram referidos neste estudo por letras de A-J, considerando a ordem que as entrevistas foram realizadas.

\subsection{Aspectos éticos}

Esse estudo foi submetido (Processo $N^{\circ}$ 23083.030577/2017-25) e aprovado ( $N^{\circ}$ 21349/2017) pelo Comitê de Ética 
em Pesquisa da Universidade Federal Rural do Rio de Janeiro (COMEP-UFRRJ). Antes da coleta de dados, todos os participantes desse estudo assinaram o Termo de Consentimento Livre e Esclarecido (TCLE).

\subsection{Coleta de dados}

Após aprovação no COMEP-UFRRJ, a pesquisa foi apresentada à direção e professores de EF de duas escolas, uma situada no município de Seropédica e a outra no município do Rio de Janeiro. A escolha das escolas para o desenvolvimento da pesquisa foi feita de forma intencional, atendendo a critérios de acessibilidade geográfica. Para os professores que demonstraram interesse em participar da pesquisa foi entregue o TCLE. Após leitura, preenchimento e assinatura do TCLE, foram realizadas as entrevistas, no mesmo dia e individualmente. Os dados foram coletados entre abril e agosto de 2018.

Utilizou-se a entrevista semiestruturada como instrumento de coleta de dados, com perguntas abertas e fechadas (Triviños, 1987; Manzini, 2004). Para tal, foi previamente elaborado um roteiro de entrevista composto por seis perguntas acerca da Lei $\mathrm{n}^{\circ}$ 10.639/03, buscando analisar a formação profissional acerca da Lei, bem como o conhecimento, a apropriação, a proposta (se há ou não na disciplina), as possíveis dificuldades e a percepção de importância do desenvolvimento de conteúdos relativos a cultura afro-brasileira por professores de EF. Após elaboração, o roteiro foi analisado por dois professores da universidade. As entrevistas foram realizadas individualmente, gravadas em áudio e transcritas para posterior análise dos dados.

\subsection{Análise de dados}

A análise de dados foi realizada mediante Técnica de Análise de Conteúdo proposta por Bardin (2011), organizada em três fases fundamentais: pré-análise; exploração do material; e tratamento dos resultados - categorização, inferência, descrição e interpretação.

A partir das transcrições, os dados foram analisados considerando três categorias a priori, sabendo elas: conhecimentos acerca da inclusão da cultura afro-brasileira nas aulas de educação física; desafios na abordagem de conteúdos relativos à cultura afro-brasileiro nas aulas de educação física; e, por fim, percepções sobre a importância da inclusão de conteúdos relativos à cultura afro-brasileira nas aulas de educação física, apresentados a seguir.

\section{Resultados}

Os resultados foram organizados considerando os três grupos categorizados e analisados, apresentados na seção anterior. Cada grupo contempla algumas das seis questões da entrevista, sendo estas sinalizadas antes da apresentação dos dados.

\subsection{Conhecimentos acerca da inclusão da cultura afro-brasileira nas aulas de educação física}

Você conhece a Lei no $10.639 / 03$ ?

Ao questionar se conheciam a Lei $\mathrm{n}^{\circ} 10.639 / 03$, oito professores alegaram desconhecê-la e dois professores afirmaram conhecê-la, observando-se que a maioria não a conhecia.

Quais os conteúdos abordados em suas aulas?

Em relação aos conteúdos abordados nas aulas de EF, destacou-se os "jogos", seguido de "esportes" e "dança". Os conteúdos menos citados foram: "folclore", "recreação" e, por fim, "étnico-racial".

Entre estes conteúdos, há algum conteúdo relacionado à cultura afro-Brasileira? Se sim, como e quando esses conteúdos são trabalhados? 
Ao realizar essa pergunta, cinco professores indicaram desenvolver conteúdos que valorizam a cultura afro-brasileira dentro de seus conteúdos abordados nas aulas. No entanto, apenas uma professora declarou trabalhar a cultura afro-brasileira perpassando todos os conteúdos e bimestres - que é o previsto pela Lei 10.639/03 e recomendado pelas Diretrizes Curriculares Nacionais, como vê-se abaixo:

“[...] esses conteúdos são trabalhados perpassando desde o início do primeiro bimestre até o final. Por que não é só em novembro que você tem que falar, ou em maio que você tem que falar numa festa cíclica, sobre a questão da cultura afro-brasileira ou sobre a cultura indígena". (F) folclórica.

E, na fala dos quatro demais professores é possível observar que o conteúdo é desenvolvido de forma pontual ou

"[...] Sim, nas danças folclóricas do Brasil, algumas danças de origem africana, e capoeira" (A)

"[...] Sim, foi a abordagem teatral envolvendo o conteúdo de atividades rítmicas" (B)

"[...] "Sim, eu pretendo trabalhar com dança no mês de novembro que é o mês que a gente fala sobre consciência negra" $(\mathrm{C})$

"[...] Sim, nas danças folclóricas, no terceiro bimestre" (E)

A interpretação dessas respostas aponta que a cultura afro-brasileira é trabalhada na escola, na maioria das vezes, reduzida a conteúdos ilustrativos, em datas comemorativas, não perpassando o cotidiano escolar.

\subsection{Desafios na abordagem de conteúdos relativos à cultura afro-brasileiro nas aulas de educação física}

Você sente/sentiria dificuldade em desenvolver conteúdos relacionados às manifestações afro-brasileiras? Exemplifique.

Ao pergunta-los sobre as possíveis dificuldades para desenvolver conteúdos relacionados às manifestações afrobrasileiras, oito professores declararam enfrentar dificuldades, destacando-se o preconceito da comunidade escolar, seguido da falta de conhecimento de como abordar tais conteúdos. Em relação à maior dificuldade sinalizada, o professor A relata que: “[...], os alunos ficam receosos de fazer a aula, pois associam à religião afro e não é bem visto pelos alunos e famílias da religião protestante".

Você teve na sua formação conteúdos acerca da valorização das manifestações afro-brasileiras? Quais?

Também, é possível relacionar esses resultados com a formação docente dos entrevistados. Isso, pois, verifica-se que os desafios e o despreparo dos professores podem ser provenientes da ausência de contato de oito dos dez indivíduos com o tema durante a formação profissional. Alguns dos oito professores acreditam que a falta de contato com conteúdos afrobrasileiros durante a formação tenha relação com o ano em que cursaram a licenciatura. Por isso, os respectivos professores mencionaram o tempo da graduação em suas respostas: "Na verdade a minha formação é de noventa e seis [...] Na época que eu lembre não tinha nenhuma disciplina específica" (C); "Não tive. Na época que me formei, não tive não" (D); e "[...] no caso eu me formei em mil novecentos e noventa e dois, essa lei não existia" (E).

Das duas professoras que afirmaram ter vivenciado tais conteúdos durante a formação, a professora B relata o contato em fatos isolados e a professora F relata que vivenciou na sua segunda graduação (em dança), como apresenta-se a seguir:

Tive sim. Mas, em fatos isolados, por exemplo, na disciplina de história, que é uma disciplina que traz à tona esses conteúdos, ela foi trabalhada e dentro, ao longo da minha época era primeiro e segundo graus [...] Eu tive apontamentos, mas dentro da disciplina de história, dentro da disciplina de filosofia que foi trabalhada só na faculdade, quando eu fiz a minha primeira faculdade que foi administração de empresas, dentro da disciplina de sociologia. [...] E no curso de educação física já depois do ano 2000, a gente já tinha tido a LDB. Durante a faculdade eu só não tive as abordagens, na disciplina de atividades rítmicas na época que eu fiz, que era dança, aprender sobre a cultura étnico-racial dos grupos de danças folclóricas... (B).

"[...] tive maracatu. Tive jongo na faculdade também. Na minha formação, não na, na escola, mas minha formação como professora de dança [...]" (F). 
Com isso, é possível analisar que a abordagem da cultura afro-brasileira durante a formação inicial em EF, sobretudo do grupo investigado, é inexistente ou insuficiente. Assim, vê-se que o desafio ainda é grande, pois muitos professores não estão preparados para lidar com determinadas situações referentes a questões teórico-metodológicas, as quais emergiram com a aprovação da Lei em questão, gerando inquietações e dúvidas nos meios escolares e acadêmicos.

\subsection{Percepções sobre a importância da inclusão de conteúdos relativos à cultura afro-brasileira nas aulas de educação física}

Você considera necessário o desenvolvimento de conteúdos referentes à cultura Afro-Brasileira nas aulas de Educação Física? Por quê?

Nove professores consideram importante o desenvolvimento do conteúdo afro-brasileiro nas aulas de EF escolar. No entanto, o professor D e a professora B só concordam se houver o desenvolvimento de todas as culturas. A professora $\mathrm{F}$ considera importante, mas fala sobre a necessidade da interdisciplinaridade: “[...] olha eu não acho que é dissociado de outras disciplinas, não especificamente só na educação física. A educação física sozinha também não funciona. Então eu acho que precisa ter esse entendimento interdisciplinar". Na opinião do professor H é importante, mas deveria ser mais estudado. Para a professora $\mathrm{C}$, para incluir o conteúdo nas aulas é necessário arrumar um meio de trabalhar junto com a família, na tentativa de reduzir o preconceito:

“[...] O problema é: e os pais né? O ideal seria que a gente tivesse uma... eu não sei, talvez uma atividade que incluísse os pais, a família... eu não sei... porque o preconceito já vem da própria família. Então (risos), quer dizer a gente tenta, né? A gente tenta incluir todo mundo, mas é complicado. Então acho que é importante, já na escola a gente começar o debate. Eu acho que começar o debate, fazer seminário sobre a questão... é... vai ser uma polêmica, vai ser uma discussão, mas eu acho que para a gente começar a falar sobre o assunto na escola, eu acho importante, está? Porque eles só têm a visão, né? Da família. Então começar a abrir a visão deles e mostrar... eu acho importante! " (C)

A diversidade e/ou miscigenação aparece em quatro justificativas acerca da importância do ensino da cultura afro-

brasileira nas aulas de EF:

"Totalmente favorável! Como eu acabei de falar. O negro, ele faz parte dessa cultura brasileira, como um dos povos formadores da nossa nação." (E)

"[...] é totalmente importante porque somos brasileiros e nós somos um povo extrema. É o povo mais miscigenado que tem no mundo". (F)

“[...] então eu acho que é importante sim esse tema ser abordado porque a gente tá num país que é miscigenado né?" (I)

"Sim, porque o nosso povo é muito mesclado. Temos povos de várias culturas e é de grande valia ter isso nas aulas de educação física." (J)

Ademais, dois professores justificam a importância devido ao preconceito ainda presente na sociedade. Assim como relata a professora B "[...] e acho importante trabalhar sim a questão étnico-racial por conta do processo de discriminação que a gente ainda vive no nosso país”. E, por fim, a professora C “[...] é tanto preconceito, então eu acho importante justamente para mudar essa visão. Eu acho que a gente tem que começar a trabalhar na escola".

\section{Discussão}

Nos últimos dezoito anos a urgência das discussões acerca da discriminação racial na sociedade resultou em políticas governamentais a favor da igualdade racial como, por exemplo, a criação de cotas raciais e a obrigatoriedade do ensino das manifestações africanas, afro-brasileiras e indígenas na educação básica. A partir da inclusão da Lei 10.639/03 no contexto educacional brasileiro, o professor passou a se configurar como o centro de busca para alcançar a inclusão. Sendo assim, considerando a atual conjuntura, é fundamental entender a formação dos professores para além do conhecimento sobre essa Lei, mas também pensar em meios e práticas que os auxiliarão no desenvolvimento do conteúdo proposto por essas políticas. 
Por isso, esperava-se que os docentes ao menos tivessem ouvido falar sobre a Lei, porém apenas dois professores nessa pesquisa afirmaram conhecer a legislação em questão e apenas um professor teve contato de forma parcial com o conteúdo durante a formação em EF. Diante dessa realidade, é possível notar a ausência de relação dos professores de EF investigados com a cultura afro-brasileira e a importância que as escolas dão ao se tratar de relações étnico-raciais. A formação dos professores, no que se refere à História da África, ainda está muito aquém do que a atualidade exige para o ensino da História dos povos Africanos e Afro-brasileiros (Oliveira, 2016).

Os professores de EF escolar ainda utilizam os conteúdos jogos e esportes como predominantes em suas aulas, demostrando que a disciplina ainda carrega sua herança advinda do período esportivista. Isto é, mesmo existindo outras propostas de trabalho para a EF escolar, ainda é perceptível a predominância esportiva (Bento, 2012). Porém o conteúdo referente a dança aparece em quatro respostas dos entrevistados, apontando que a disciplina pode estar caminhando para uma mudança paradigmática.

Quatro professores afirmaram incluir a cultura afro-brasileira entre os conteúdos que utilizam, contudo apenas uma professora aborda a temática de acordo com o previsto pelas Diretrizes Curriculares Nacionais para a Educação das Relações Étnico-Raciais e para o Ensino de História e Cultura Afro-Brasileira e Africana, que determina que:

[...] - O ensino de História e de Cultura Afro-Brasileira, se fará por diferentes meios, inclusive, a realização de projetos de diferentes naturezas, no decorrer do ano letivo, com vistas à divulgação e estudo da participação dos africanos e de seus descendentes em episódios da história do Brasil, na construção econômica, social e cultural da nação, destacando-se a atuação de negros em diferentes áreas do conhecimento, de atuação profissional, de criação tecnológica e artística, de luta social [...]

- O ensino de História e Cultura Africana se fará por diferentes meios, inclusive a realização de projetos de diferente natureza, no decorrer do ano letivo, com vistas à divulgação e estudo da participação dos africanos e de seus descendentes na diáspora, em episódios da história mundial, na construção econômica, social e cultural das nações do continente africano e da diáspora, destacando-se a atuação de negros em diferentes áreas do conhecimento, de atuação profissional, de criação tecnológica e artística, de luta social [...] (Brasil, 2004b, p. 22-23).

Sendo assim, as Diretrizes Curriculares recomendam que a valorização da cultura e história afro-brasileira e africana seja realizada ao longo do ano letivo e abordando diversas esferas sociais. Apenas uma professora trabalha o conteúdo da maneira exigida e os demais trabalham de maneira pontual. Essa abordagem pontual não garante a efetividade da educação étnico-racial, pois o conteúdo acaba sendo transmitido parcialmente. Incluir o conteúdo afro-brasileiro nos currículos e Projetos Políticos Pedagógicos é um desafio para a educação, pois é preciso preparação e planejamento da comunidade escolar.

Há um grande leque de possibilidades para trabalhar a cultura afro-brasileira na educação básica, de forma eficiente e reflexiva. Alguns autores apontam em suas pesquisas meios para a valorização dessa cultura em diferentes dimensões. As pesquisas de Maranhão (2009) e Bento (2012) apontam para uma versatilidade de jogos de origem afrodescendente e comprovam a eficácia de utilizar esse conteúdo nas aulas de EF. No início da intervenção realizada por Maranhão (2009), as crianças desconheciam a África e carregavam consigo ideias racistas e estereotipadas. No entanto, após realizar parte da intervenção, os alunos começaram a demonstrar uma percepção mais positiva sobre a África e os afro-brasileiros. Com isso, percebe-se que as experiências e os diálogos sobre a cultura negra são fundamentais para afirmar, conhecer e respeitar as diferentes culturas e identidades.

A capoeira se mostra como uma possibilidade acessível para ser trabalhada nas aulas de EF. Impolcetto et al. (2013) afirmam que introduzir didaticamente a "capoeira da escola" é necessário para que ela possa ser praticada em todas as suas multifaces de luta, arte, ritmo, jogo, instrumentação, brincadeira, expressão corporal, historicidade. Recomenda-se ao professor abordar a origem da capoeira e seu processo histórico, de prática proibida a patrimônio imaterial da cultura brasileira. O caderno de Orientações e Ações para a Educação das Relações Étnico-Raciais (Brasil, 2006) também possui sugestões de 
atividades que podem ser utilizadas especificamente em cada nível de ensino e para diversas disciplinas e áreas de conhecimento, contemplando as dimensões conceitual, procedimental e atitudinal.

Em função das dificuldades encaradas pelos professores, foi possível analisar nas entrevistas que são incluídos, predominantemente, o preconceito da comunidade escolar, seguido da falta de preparo e contato com o conteúdo (que está conectado ao déficit em sua formação profissional). Segundo Gomes (2012), na escola, no currículo e na sala de aula convivem de maneira tensa: valores, ideologias, símbolos, interpretações, vivências e preconceitos. Nesse contexto, a discriminação racial está presente como fator de seletividade na instituição escolar e o silêncio é um dos rituais pedagógicos pelo qual ela se expressa.

O preconceito religioso também pode ser considerado como discriminação racial e não aparece apenas na EF, mas em todos os componentes curriculares e na sociedade em geral desde a colonização. De acordo com Carreira e Souza (2013) o racismo está presente de forma enraizada nas instituições, sendo chamado de racismo institucional. O racismo institucional aumenta as barreiras para o acesso à aprendizagem em um sistema educacional caracterizado historicamente por diversos problemas, desafios e desigualdades. Hoje o país ainda tem um perfil baseado no tradicionalismo e padrões eurocêntricos, nos quais os negros são inferiorizados e marginalizados, seja na escola, na mídia ou no ambiente profissional. Logo, é preciso conhecer, respeitar, valorizar e vivenciar a cultura afro-brasileira, na tentativa de reduzir os estereótipos que levam à exclusão e discriminação racial.

Apesar da maioria dos professores investigados não terem contato com o conteúdo em suas respectivas formações e sentirem dificuldades em abordar essa temática, a pesquisa revela que a maioria dos professores entrevistados acreditam que o ensino da cultura afro-brasileira nas aulas de EF é importante, seja pela diversidade cultural ou para lutar contra o preconceito. Corroborando com esse achado, Cavalleiro (2005) afirma que os professores se dizem preocupados com a discriminação racial e os preconceitos presentes no cotidiano escolar, porém se mostram desconhecedores de práticas pedagógicas antirracistas e de leituras que os amparem.

Por isso, a escola precisa dar espaço e o Estado precisa dar suporte para que a Lei vigente seja cumprida. Esse é um meio para que os alunos entendam a realidade e aprendam sobre a verdadeira construção do nosso país. A partir disso, a discriminação racial e a desigualdade poderão ser reduzidas, tendo em vista que na maioria dos casos o preconceito provém da falta de conhecimento e a maioria das pessoas não são capazes de reconhecer quando têm atitudes racistas. Para Henriques (2002), as modificações estruturais no interior da escola remontam a possibilidade de quebra dos mecanismos que reproduzem as atitudes e discursos racistas. Destacam-se a redefinição do conteúdo estereotipado dos livros didáticos e a inclusão de conteúdos nos currículos escolares que valorizem a cultura afro-brasileira para, desse modo, contribuir no resgate da autoestima das crianças negras e na redução dos territórios de tolerância, tradicionalmente alimentados pela ignorância.

Em suma, existem diversas lacunas que atravessam a aplicabilidade da Lei em questão (nº 10.639/03) e, para que seja possível colocá-la em prática, é necessário, para além de um currículo que permita a sua efetivação, o empenho dos atores envolvidos, isto é, que a prática pedagógica considere o contexto da diversidade, afastando-se cada vez mais dos conteúdos escolares pautados em discursos eurocêntricos (Santos \& Alves, 2021). Ainda no que diz respeito aos professores, os resultados dessa pesquisa corroboram com os achados de Alves et al. (2021), pois de oito professores investigados em sua pesquisa, apenas um demonstrou conhecimento sobre a Lei e, de maneira geral, percebeu-se superficialidade e restrito domínio teóricoconceitual na tratativa da temática (Educação para as Relações Étnico-Raciais). Esse déficit pode ser resultado, em parte, da formação acadêmica, pois três relataram não ter tido conhecimentos sobre o Ensino da História e da Cultura Afro-brasileira e os quatro que tiveram contato na formação inicial revelaram que a abordagem acontecia raramente. Assim, foi possível observar certa fragilidade na formação de professores em função dessa temática (Alves, et al., 2021). 
Outros estudos (Pinto, et al., 2014; Pires \& Souza, 2015; Santos, et al., 2020) também corroboram com os resultados encontrados. Ao analisarem o trato pedagógico das práticas corporais de origem afro-brasileira e africana na EF escolar, em uma turma de oitavo ano do ensino fundamental de uma escola municipal, os autores incluíram em suas considerações finais alguns limites encontrados na prática pedagógica, sendo um deles a ausência de conteúdos voltados à implementação da Lei $\mathrm{n}^{\circ}$ 10639/03, tendo tido contato apenas com uma disciplina na formação do curso em Licenciatura em Educação Física (Pinto, et al., 2014).

Buscando analisar a legalidade do ensino da cultura afro-brasileira (Lei $\mathrm{n}^{\circ}$ 10.639/03) no trabalho pedagógico de dezessete professores de EF, as autoras propuseram grupos focais. Com base nas falas dos professores, constatou-se certo estranhamento acerca da cultura afro-brasileira e africana. Ainda, esse estranhamento se subdividiu entre: o desconhecimento da existência da Lei - fato que corrobora os resultados do presente estudo, e a capoeira como única forma de trabalhar a cultura afro-brasileira (Pires \& Souza, 2015).

Com o intuito de analisar a abordagem ou não da cultura afro-brasileira por professores do ensino fundamental I, de escolas municipais, utilizando como estratégia a dança nas aulas de EF, as autoras constataram que embora os professores identifiquem o trato dos conteúdos da cultura afro-brasileira como parte integrante do currículo, apenas quatro dos sete trabalham atividades dentro desse conteúdo. Contudo, dos quatro professores, apenas dois indicaram trabalhar a história de forma crítica, com intencionalidade, isto é, sem propor atividades desconexas. Assim, considera-se que a abordagem dos conteúdos acontece em parte. Diferente dos resultados encontrados nesse estudo, todos os professores afirmaram ter tido conhecimento da história e cultura afro-brasileira, advindo da graduação ou campo de trabalho (Santos, et al., 2020).

O racismo, o preconceito, a discriminação, o pensamento eurocentrado estão presentes em nossa sociedade (Lima, et al., 2020; Alves, et al., 2021; Santos \& Alves, 2021) e para combatê-los é preciso que haja um trabalho de “[...] conscientização político-social de pertencimento e constituição da identidade negra.” (Lima, et al., 2020, p. 10). A valorização da cultura afrobrasileira é considerada um problema social que atravessa a instituição escolar, sendo imprescindível a sua inclusão nas práticas desenvolvidas na escola para que seja possível caminhar rumo a democratização do ensino (Lima, et al., 2020). A abordagem dessa temática deve acontecer em todo o currículo escolar e, para isso, os professores precisam se apoderar desses conhecimentos, utilizando, sobremaneira, de sua autonomia (Santos \& Alves, 2021), tendo em vista as fragilidades que aconteceram e/ou que possam vir a ocorrer em suas formações profissionais.

Dessa forma, é preciso ampliar a valorização e representatividade do negro e afrodescendente na escola, assim como adotar discursos antirracistas. Com isso, será possível, por exemplo, contribuir para o exercício de direitos, para a formação identitária e para o conhecimento acerca da história da educação do negro brasileiro. "Esse ofício é um processo longo, contínuo e de muito trabalho de conscientização, discussões e resistências.” (Lima, et al., 2020, p. 12) e, para tal, “[...] a categoria Formação de Professores/as torna-se fundamental para viabilizar a formação cidadã aos/as discentes.” (Alves, et al., 2021, p. 13).

\section{Considerações Finais}

Considerando os professores investigados nesse estudo, é possível considerar que embora passada mais de uma década de sancionada a Lei $\mathrm{n}^{\circ}$ 10.639/03, ainda existem professores que não a conhecem e/ou possuem pouco conhecimento acerca de seu conteúdo e implementação nas escolas. Como consequência, essa falta de conhecimento reflete nos conteúdos propostos e desenvolvidos nas aulas, tendo em vista que conteúdos afro-brasileiros ainda são pouco desenvolvidos e, além disso, quando abordados, geralmente, acontecem pontualmente em momentos e/ou datas específicas do calendário nacional ou, ainda, por um curto período. Essa realidade limita o conhecimento acerca da nossa cultura e folcloriza o tema, quando na verdade o objetivo da Lei é de buscar a igualdade no currículo escolar. Se a cultura europeia é discutida nas escolas 
perpassando todos os bimestres, por que falar sobre cultura afro-brasileira só em épocas convenientes para o sistema educacional?

Observou-se também que além da insegurança e despreparo para abordar a cultura afro-brasileira, os professores enfrentam outra dificuldade no ambiente escolar: o preconceito. A resistência da comunidade escolar desestimula e os prejudica na tentativa de incluir tais conteúdos em suas aulas. Essa realidade é reflexo da intolerância religiosa e do racismo que ainda estão enraizados na sociedade, inferiorizando práticas da cultura negra. Essa discriminação pode ser reduzida através da educação, no entanto, como professores serão aptos para enfrentar esses conflitos e trabalhar de forma efetiva se os mesmos estão despreparados?

Em relação ao despreparo, foi possível observar que ainda há certo déficit na formação dos professores de EF, tratando-se de relações étnico-raciais. Normalmente os cursos de licenciatura em EF possuem apenas uma disciplina específica de relações étnico-raciais em um período de formação que dura, no mínimo, quatro anos. A proposta não é incluir mais uma disciplina no currículo, mas desenvolver o ensino e a valorização das manifestações afro-brasileiras no planejamento das disciplinas durante a graduação. Ainda que os professores de EF investigados não tenham profundo conhecimento da cultura afro-brasileira e suas respectivas formações, ou até os próprios sejam negligentes em relação a esse conteúdo, a grande maioria considera que a inclusão desses conteúdos nas aulas é importante.

Apesar dessa situação, observou-se uma evolução paradigmática nos conteúdos escolhidos pelos professores de EF. Embora os jogos e os esportes tenham aparecido em maior frequência nos resultados, muitos professores passaram a adotar outros conteúdos em suas aulas, como a dança e o folclore. Esse pode ser considerado um passo significativo para a evolução na forma em que a EF é desenvolvida. Inclusive, essa diversidade de conteúdos utilizados demostra que a EF é capaz de abordar a cultura afro-brasileira em seu projeto, porém falta preparo e, provavelmente, efetivo interesse.

É preocupante a falta de conhecimento dos professores acerca da Lei 10.639/03, principalmente porque todos os professores entrevistados lecionam em escolas da rede pública, local em que o alunado negro aparece em grande número. É preciso falar e ensinar, pois um problema não some da sociedade quando é silenciado. A reflexão que fica após o desenvolvimento desse estudo é: até que ponto incluir a valorização da cultura afro-brasileira nos currículos é interessante para aqueles que fazem parte da construção do sistema educacional no Brasil? Pois há uma persistente resistência na desconstrução do currículo tradicionalmente eurocêntrico, mesmo sendo de comum conhecimento a importância em valorizar e respeitar a diversidade. A negligência ao continente africano está diretamente relacionada aos interesses políticos e econômicos. Afinal, quais as contribuições do ensino dessa cultura para o nosso sistema educacional hegemônico?

Por fim, os resultados deste estudo indicam a importância, necessidade e urgência de novas investigações acerca da Educação das Relações Étnico-Raciais, bem como voltadas ao desenvolvimento de conteúdos relativos a cultura afro-brasileira na EF escolar, pois estes assuntos estão associados a um problema histórico de construção de ideias que legitimam o eurocentrismo, reproduzido também nas escolas e nas aulas de EF. Portanto, indica-se novas pesquisas em diferentes contextos, investigando professores, alunos e demais membros da comunidade escolar, buscando ampliar a análise e discussão a respeito dessa temática. Pois, embora crescente discussão acerca da Educação das Relações Étnico-Raciais, são relevantes investigações que possam contribuir rumo à legitimação e valorização das diferentes manifestações culturais na prática pedagógica e escolar.

\section{Referências}

Alves, S. S., Vieira, S. S., Stoll, V. G. \& Lima, Q. C. E. (2021). Educação para as Relações Étnico-Raciais: concepções e práticas dos/as docentes da Educação Infantil. Research, Society and Development, 10(3), e12810313141. https://doi.org/10.33448/rsd-v10i3.13141 
Anjos, R. S. A. (2005). A África, a educação brasileira e a geografia. In: Educação anti-racista: caminhos abertos pela Lei Federal nº 10.639/03. Brasília: Ministério da Educação, Secretaria de Educação Continuada, Alfabetização e Diversidade. http://etnicoracial.mec.gov.br/publicacoes/item/9-educacao-antiracista-caminhos-abertos-pela-lei-federal-n-10-63903

Bardin, L. (2011). Análise de conteúdo. Edições 70.

Bento, C. C. (2009). Jogos de diferentes culturas na Educação Física escolar. In: Anais do IV Colóquio de Pesquisa Qualitativa em Motricidade Humana: as lutas no contexto da motricidade, III Simpósio sobre o Ensino de Graduação em Educação Física: 15 anos do Curso de Educação Física da UFScar, V ShotoWorkshop. 622-632. http://www.ufscar.br/ defmh/spqmh/pdf/2009/bento_jogos.pdf

Bento, C. C. (2012). Jogos de origem ou descendência indígena e africana na educação física escolar: educação para e nas relações étnico-raciais. Dissertação (Mestrado em Educação) - Universidade Federal de São Carlos, São Carlos/SP.

Bosi, A. (1992). Dialética da colonização. Companhia das Letras.

Brasil. (1996). Lei $n^{\circ}$ 9.394, de 20 de dezembro de 1996. Estabelece as diretrizes e bases da educação nacional. Presidência da República, Casa Civil, Subchefia para Assuntos Jurídicos, Brasília. http://www.planalto.gov.br/ccivil_03/leis/19394.htm

Brasil. (1997). Parâmetros Curriculares Nacionais: pluralidade cultural, orientação sexual. Secretaria de Educação Fundamental. MEC/SEF. http://portal.mec.gov.br/seb/arquivos/pdf/livro101.pdf

Brasil. (2003a). Lei $n^{\circ}$ 10.639, de 9 de janeiro de 2003. Altera a Lei no 9.394, de 20 de dezembro de 1996. Presidência da República, Casa Civil, Subchefia para Assuntos Jurídicos, Brasília. http://www.planalto.gov.br/ccivil_03/leis/2003/110.639.htm

Brasil. (2003b). Decreto $n^{\circ} 4.886$, de 20 de novembro de 2003. Institui a Política Nacional de Promoção da Igualdade Racial - PNPIR e dá outras providências. Presidência da República, Casa Civil, Subchefia para Assuntos Jurídicos, Brasília. http://www.planalto.gov.br/ccivil_03/decreto/2003/d4886.htm

Brasil. (2004a). Parecer $N^{o}$ CNE/CP 003/2004. Diretrizes Curriculares Nacionais para a Educação das Relações Étnico-Raciais e para o Ensino de História e Cultura Afro-Brasileira e Africana. Ministério da Educação, Conselho Nacional de Educação. http://portal.mec.gov.br/dmdocuments/cnecp_003.pdf

Brasil. (2004b). Diretrizes Curriculares Nacionais para a Educação das Relações Étnico-Raciais e para o Ensino de História e Cultura Afro-Brasileira e Africana. Brasília, DF. https://www.gov.br/inep/pt-br/centrais-de-conteudo/acervo-linha-editorial/publicacoes-diversas/temas-interdisciplinares/diretrizescurriculares-nacionais-para-a-educacao-das-relacoes-etnico-raciais-e-para-o-ensino-de-historia-e-cultura-afro-brasileira-e-africana

Brasil. (2006). Orientações e Ações para a Educação das Relações Étnico-Raciais. Ministério da Educação, Secretaria da Educação Continuada, Alfabetização e Diversidade. Brasília: SECAD. http://portal.mec.gov.br/dmdocuments/orientacoes_etnicoraciais.pdf

BRASIL. (2016a). Síntese de Indicadores Sociais. Uma análise das condições de vida da população brasileira. Ministério do Planejamento, Desenvolvimento e Gestão. Instituto Brasileiro de Geografia e Estatística, IBGE. https://biblioteca.ibge.gov.br/index.php/biblioteca-catalogo?view=detalhes\&id=298965

BRASIL. (2016b). Pesquisa Nacional por Amostra de Domicílios Contínua. Características gerais dos domicílios e dos moradores. Ministério do Planejamento, Desenvolvimento e Gestão. Instituto Brasileiro de Geografia e Estatística, IBGE. https://biblioteca.ibge.gov.br/index.php/bibliotecacatalogo?view $=$ detalhes\&id $=2101377$

Brasil. (2017). Base Nacional Comum Curricular. Educação é a Base. Ministério da Educação, Secretaria de Educação Básica, Conselho Nacional de Educação. http://basenacionalcomum.mec.gov.br/images/BNCC_EI_EF_110518_versaofinal_site.pdf.

Carreira, D. \& Souza, A. L. S. (2013). Indicadores da qualidade na educação: relações raciais na escola. Ação Educativa.

Cavalleiro, E. (2005). Introdução. In: Educação anti-racista: caminhos abertos pela Lei Federal n 10.639/03. Brasília: Ministério da Educação, Secretaria de Educação Continuada, Alfabetização e Diversidade. http://etnicoracial.mec.gov.br/publicacoes/item/9-educacao-anti-racista-caminhos-abertos-pela-lei-federaln-10-63903

Daólio, J. (2005). A Educação Física como prática cultural: tensões e riscos. Revista Pensar a Prática, Goiânia, 8(2), 215-226. https://doi.org/10.5216/rpp.v8i2.32374

Darido, S. C. (2001). Os conteúdos da Educação Física escolar: influências, tendências, dificuldades e possibilidades. Perspectivas em Educação Física Escolar, Niterói, 2(1), 5-25.

Darido, S. C., Rangel-Betti, I. C., Ramos, G. N. S., Galvão, Z, Ferreira, L. A., Mota e Silva, E. V., Rodrigues, L. H., Sanches, L., Pontes, G. \& Cunha, F. (2001). A Educação Física, a formação do cidadão e os Parâmetros Curriculares Nacionais. Revista Paulista de Educação Física, São Paulo, 15(1), 17-32. http://citrus.uspnet.usp.br/eef/uploads/arquivo/v15\%20n1\%20artigo2.pdf

Filho, J. B. S. (2006). História do negro no Brasil. In: Siss, A. \& Oliveira, I. População Negra e educação escolar. UFF: Cadernos do Programa de Educação sobre o Negro na Sociedade Brasileira.

Gil, A. C. (2008). Métodos e Técnicas de Pesquisa Social. (6a ed.), Editora Atlas S.A.

Góis Junior, E. (2000). Os higienistas e a Educação Física: a história dos seus ideais. Dissertação (Mestrado em Educação Física) - Universidade Gama Filho, Rio de Janeiro.

Gomes, N. L. (2002). Educação e Identidade Negra. Aletria: Revista de Estudos de Literatura, 9, 38-47. https://doi.org/10.17851/2317-2096.9.38-47

Gomes, N. L. (2012). Relações Étnico-Raciais, educação e descolonização dos currículos. Currículo sem Fronteira, 12(1), 98-109. http://www.apeoesp.org.br/sistema/ck/files/5_Gomes_N\%20L_Rel_etnico_raciais_educ\%20e\%20descolonizacao\%20do\%20curriculo.pdf 
Henriques, R. (2002). Raça e gênero no sistema de ensino: os limites das políticas universalistas na educação. UNESCO.

Impolcetto, F. M., Terra, J. D., Rosário, L. F. R. \& Darido, S. C. (2013). As práticas corporais alternativas como conteúdo da Educação Física escolar. Revista Pensar a Prática, Goiânia, 16(1), 267-281. https://doi.org/10.5216/rpp.v16i1.15213

Kruppa, S. M. P. (2016). Sociologia da educação. Cortez Editora.

Lima, V. S., Nunes, A. \& Braga, E. S. O. (2020). Oralidade africana e cultura afro-brasileira no ambiente educacional: algumas reflexões. Research, Society and Development, 9(4), e99942888. http://dx.doi.org/10.33448/rsd-v9i4.2888

Manzini, E. J. (2004). Entrevista semi-estruturada: análise de objetivos e de roteiros. In: Anais do Seminário Internacional sobre pesquisa e estudos qualitativos. Bauru: USC.

Maranhão, F. (2009). Jogos africanos e afro-brasileiros nas aulas de Educação Física: processos educativos das relações étnico-raciais. Dissertação (Mestrado em Ciências Humanas) - Universidade Federal de São Carlos, São Carlos.

Minayo, M. C. S. (2002). Ciência, técnica e arte: o desafio da pesquisa social. In: Minayo, M. C. S. (Org.). Pesquisa social: teoria, método e criatividade. Petrópolis/RJ: Editora Vozes.

Miranda, C. \& Rosa, M. (2014). Igualdade étnico-racial na sala de aula: práticas interculturais em uma escola pública do município de Duque de Caxias-RJ. In: Gouvêa, F. C. F., Oliveira, L. F. \& Sales, S. R. Educação e Relações Étnico-Raciais. Entre diálogos contemporâneos e políticas públicas. Petrópolis, RJ: De Petrus et Alii; Brasília, DF: CAPES. https://cursos.ufrrj.br/posgraduacao/ppgeduc/files/2015/03/Miolo_Educacao_e_Relacoes_Etnico-raciais.pdf

Moreira, A. J. \& Silva, M. C. P. (2010). A Lei n 10.639/03 e a Educação Física: memórias e reflexões sobre a educação eugênica nas políticas de formação de professores. Lecturas: Educación Física y Deportes, Buenos Aires, (146). https://www.efdeportes.com/efd146/a-lei-10639-03-e-a-educacao-fisicaeugenica.htm

Moreira, A. J. \& Silva, M. C. P. (2018). Possibilidades didático-metodológicas para o trato com a Lei n ${ }^{\circ} 10.639 / 2003$ no ensino da Educação Física: a importância da Educação Étnico-Racial. Holos, 1, 193-200. https://doi.org/10.15628/holos.2018.2891

Munanga, K. (2015). Por que ensinar a história da África e do negro no Brasil de hoje? Revista do Instituto de Estudos Brasileiros, Brasil, 62, 20-31. https://www.revistas.usp.br/rieb/article/view/107184/105723

Oliveira, S. M. S. (2016). Formação de professores e ensino de história da África e cultura afro-brasileira e africana: saberes e práticas. Dissertação (Mestrado em Educação) - Universidade Estadual do Ceará, Fortaleza/Ceará.

Oliveira, R. C. \& Daolio, J. (2010). Educação Física, cultura e escola: da diferença como desigualdade à alteridade como possibilidade. Movimento - Revista de Educação Física da UFRGS, Porto Alegre, 16(1), 145-167. https://doi.org/10.22456/1982-8918.8279

Pereira, J. S. (2011). Diálogos sobre o Exercício da Docência - recepção das leis 10.639/03 e 11.645/08. Educação \& Realidade, Porto Alegre, 36(1), 147-172. https://seer.ufrgs.br/educacaoerealidade/article/view/15073/11515

Pinto, F. M., Macamo, A. J. \& Azevedo, N. (2014). Ensinando práticas corporais de origem afrobrasileira e africana na Educação Física escolar. Revista Brasileira de Ciências do Esporte, Florianópolis, 36(2), S370-S384. http://revista.cbce.org.br/index.php/RBCE/article/view/2139

Pires, J. V. L. \& Souza, M. S. (2015). Educação Física e a aplicação da Lei no 10.639/03: análise da legalidade do ensino da cultura afro-brasileira e africana em uma escola Municipal do RS. Movimento, Porto Alegre, 21(1), 193-204. https://www.seer.ufrgs.br/Movimento/article/view/46624/33309

Santos, J. L. R. \& Souza, M. E. V. (2014). De A(bdias) à Z(umbi): lembrando que nossa luta não começou agora, e nem termina aqui... In: Gouvêa, F. C. F., Oliveira, L. F. \& Sales, S. R. Educação e Relações Étnico-Raciais. Entre diálogos contemporâneos e políticas públicas. Petrópolis, RJ: De Petrus et Alii; Brasília, DF: CAPES. https://cursos.ufrrj.br/posgraduacao/ppgeduc/files/2015/03/Miolo_Educacao_e_Relacoes_Etnico-raciais.pdf

Santos, K. B., De Bona, B. C. \& Torriglia, P. L. (2020). A cultura afro-brasileira e a dança na Educação Física escolar. Motrivivência, 32(62) 01-20. https://doi.org/10.5007/2175-8042.2020e66197

Santos, S. A. (2005). A Lei n ${ }^{\circ}$ 10.639/03 como fruto da luta anti-racista do Movimento Negro. In: Educação anti-racista: caminhos abertos pela Lei Federal ${ }^{\circ}$ 10.639/03. Brasília: Ministério da Educação, Secretaria de Educação Continuada, Alfabetização e Diversidade. http://etnicoracial.mec.gov.br/publicacoes/item/9-educacao-anti-racista-caminhos-abertos-pela-lei-federal-n-10-63903

Santos, J. F. \& Alves, M. I. A. (2021). Produções científicas acerca das questões étnico-raciais presente nos Cadernos Escolares. Research, Society and Development, 10(11), e337101119649. http://dx.doi.org/10.33448/rsd-v10i11.19649

Silva, A. P. \& Filho, E. P. (2013). A Lei 10.639/03 na compreensão de professores de Educação Física: estudo de caso de Escola Municipal de São Leopoldo/RS. Identidade! São Leopoldo, 18(3), 279-290. http://periodicos.est.edu.br/index.php/identidade/article/view/1176/1139

Silva, G. S., Souza, C. V., Ribeiro, T. C. M. \& Oliveira, E. C. S. (2019). Cultura afro-brasileira: a capoeira na escola e na Educação Física. Temas em Educação Física Escolar, Rio de Janeiro, 4(2), 94-113. http://dx.doi.org/10.33025/tefe.v4i2.2247

Silva, P. B. G. (2016). Reconhecimento da história, cultura e direitos dos negros brasileiros. In: Coelho, W. N. B. \& Oliveira, J. M. Estudos sobre relações étnico-raciais e educação no Brasil. São Paulo: Livraria da Física.

Soares, D. C. (2017). As relações étnico-raciais e as TIC na educação física escolar: possibilidades para o ensino médio a partir do currículo do estado de São Paulo. Dissertação (Mestrado em Desenvolvimento Humano e Tecnologias) - Universidade Estadual Paulista, Rio Claro/SP.

Thomas, J. R., Nelson, J. K. \& Silverman, S. J. (2012). Métodos de Pesquisa em Atividade Física. (6a ed.), Artmed.

Triviños, A. N. S. (1987). Introdução à Pesquisa em Ciências Sociais: a pesquisa qualitativa em Educação. Atlas. 